\title{
Recovery of benthic macrofauna from sewage sludge disposal in the New York Bight
}

\author{
Joseph J. Vitaliano*, Steven A. Fromm, David B. Packer, Robert N. Reid, \\ Robert A. Pikanowski
}

National Marine Fisheries Service, Northeast Fisheries Science Center,
James J. Howard Marine Sciences Laboratory at Sandy Hook, 74 Magruder Rd., Highlands, New Jersey 07732, USA

\begin{abstract}
The 12-Mile Dump Site Recovery Study (12MDSRS) was a multi-year, multi-disciplinary field study to monitor the recovery of the benthic ecosystem in the inner New York (NY) Bight following termination of sewage sludge disposal in 1987. Sewage sludge had been dumped at the 12-Mile Dump Site (12MDS) for over $60 \mathrm{yr}$. In the early 1980s, the 12MDS was receiving the largest volume of sewage sludge of any dump site in the world. Monthly sampling of sediments, benthic macrofauna, and other parameters was conducted for 18 mo during phased cessation of sludge disposal and 21 mo afterward at 3 sites considered to have varying degrees of sludge influence. We used a Before-AfterControl-Impact (BACI) design in an attempt to factor out effects of background variability from the effect of termination of sludge disposal. The BACI analyses confirmed a sludge cessation effect for only some of the taxa that showed large increases in abundance after cessation. Non-metric multidimensional scaling (MDS) ordination indicated a shift in community structure at the most contaminated site towards that at the reference sites within 21 mo post cessation. Differences observed between the Pearson \& Rosenberg model and the present study appear to be related to site-specific factors in the inner NY Bight. These factors facilitated the rapid reduction of sewage sludge constituents in surficial sediments after cessation.
\end{abstract}

KEY WORDS: Benthic macrofauna $\cdot$ Sewage sludge $\cdot$ Ocean disposal $\cdot$ Recovery $\cdot$ BACI $\cdot$ Sediments · Multidimensional scaling $\cdot$ Marine ecosystem $\cdot$ New York Bight

\section{INTRODUCTION}

The planned closure in 1987 of the world's largest oceanic sewage sludge dump site, the 12-Mile Dump Site (12MDS) in the New York (NY) Bight (see Fig. 1), presented an opportunity for a field experiment to determine the effects of termination of sewage sludge disposal on important marine ecosystem components (benthic macrofauna and demersal fish assemblages, and sediment and water quality). A major consideration in the development of the 12MDS Recovery Study (12MDSRS) was the ability of the analytical techniques to distinguish between the effects of termination of sewage sludge disposal and background variability from anthropogenic and natural sources (EPD 1988,
Pikanowski 1992). Past studies at 12MDS (Pearce 1972, Botton 1979, Reid et al. 1982, Steimle et al. 1982) as well as studies at other sewage sludge dump sites (Caspers 1987, Pearson 1987, Rees et al. 1992) were unable to factor out the effects of background variability from the effects of sewage because of problems related to pseudoreplication (see EPD 1988, Pikanowski 1992). Since pseudoreplication would also be a problem during the 12MDSRS (EPD 1988, Pikanowski 1992), we used a Before-After-Control-Impact (BACI) design (Stewart-Oaten et al. 1986, EPD 1988, Pikanowski 1992) in an attempt to determine effects of cessation of sewage sludge disposal.

The Pearson \& Rosenberg (1978) model, hereafter $P \& R$, has been used in many studies to explain effects 
of organic enrichment over various temporal and spatial scales. Gray et al. (2002) questioned the predictive capabilities of the model. Maurer et al. (1993) suggested that changes in macrofaunal assemblages along a gradient of organic enrichment in open ocean, higher energy, erosional sites along the coast and shelf are different from those proposed by $P \& R$ for semienclosed, low energy, depositional sites with long residence times such as fjords and sea lochs. Other sitespecific factors may also influence the effects of organic enrichment (Savage et al. 2002) and sewage sludge (Norton \& Champ 1989) on benthic habitats. Since the NY Bight had a number of unique characteristics (listed below), it could not be certain how precisely the responses of the benthic macrofauna at the 12MDS would follow P\&R. We anticipated that there would be a decrease in the abundances of Capitella spp. and an increase in the numbers of macrofaunal species at the most sludge-influenced study site after cessation (EPD 1988).

Sewage sludge from the New York City metropolitan area had been disposed at the 12MDS since 1924. Prior to the start of phased cessation in 1986, the 12MDS was receiving up to 7.6 million tons (6.9 million t) wet weight of sewage sludge per year, which was at the time the largest known input of sewage sludge to any oceanic dump site (Norton \& Champ 1989). Although the $12 \mathrm{MDS}$ was in an open coastal area, the overall dispersive and erosional capabilities of the currents near the 12MDS were weak compared to many other sludge dump sites (Norton \& Champ 1989). However, due to local topography, shallow depth, and prevailing currents, there was no longterm accumulation of sewage sludge contaminants within the boundaries of the 12MDS (EPD 1988, Pikanowski 1992). Sediments in the nearby, deeper Christiaensen Basin and upper Hudson Shelf Valley (see Fig. 1) contain elevated concentrations of contaminants from sewage sludge as well as contaminated dredged materials from NY Harbor and outflow of the Hudson/Raritan Estuary (EPD 1988).

Although ocean disposal of sewage sludge has been discontinued at many locations (Sheppard \& Pearce 2000), there have been only a few published studies documenting the recovery of benthic macrofauna following termination of sludge disposal. Moore \& Rodger (1991) found that macrofaunal measures near a former dump site in the Firth of Clyde (Scotland) had recovered substantially 11 yr after closure. Near the Hyperion sewage sludge outfall in Santa Monica Bay, California, Dorsey et al. (1995) found that macrofaunal assemblages shifted from degraded to early transitional 5 yr after closure. In these studies, however, no attempt was made to quantitatively determine the effects of termination of disposal.
A preliminary analysis of selected benthic macrofaunal variables from the 12 MDSRS (Reid et al. 1995) indicated increases in the numbers of benthic macroinvertebrate species, species of amphipods, mollusks and polychaetes, numbers of amphipod individuals, abundances of Unciola irrorata, and decreases in the abundances of Capitella spp. at the most contaminated site after termination of disposal. However, these data were a small subset of the extensive benthic macroinvertebrate database from the study. Details about the BACI analysis and the limitations of the BACI design were not discussed. Interactions of factors that may have influenced the effects of sludge and recovery following cessation were not addressed. Because the NY Bight has unique characteristics, the results of the 12MDSRS presented in this paper will provide additional information about effects of organic enrichment and recovery on benthic macrofauna of anthropogenically stressed, open coastal environments.

\section{MATERIALS AND METHODS}

Study sites. The $12 \mathrm{MDS}$ is $22 \mathrm{~km}$ (12 nautical miles) east of Sandy Hook, New Jersey (NJ), (Fig. 1) in a shallow (20-25 m) area known as the Cholera Bank. The area of the dump site is $22.6 \mathrm{~km}^{2}$. Sediments on the Bank are medium sands. Because of shallow depth and prevailing currents, there is minimal influence of sewage sludge on the biota and sediments at the actual 12MDS. Historical data indicated that sites within the nearby deeper and lower energy Christiaensen Basin and upper Hudson Shelf Valley (Fig. 1) contained finer sediments and elevated levels of contaminants from sewage sludge as well as from other sources (EPD 1988). Study sites were therefore chosen from the Christiaensen Basin and upper Hudson Shelf Valley based on similarities in depth, sediment grain size, salinity, and seasonal water temperature cycles, and differences as stated below with respect to sludge influence on the biota and sediments (EPD 1988).

In a typical BACI design, study sites with similar environmental and biological characteristics are chosen and sampled many times in the 'before' period prior to initiation of impact at one site. Reference and impact sites are then sampled many times in the 'after' period. BACI uses abundance data for specific species at a reference site as a co-variable to factor out background variability over time for that species at the impact site (Stewart-Oaten et al. 1986, Stewart-Oaten $\&$ Bence 2001). Data from reference sites must be sufficient in both 'before' and 'after' periods to be representative of the variability over time not associated with impact. Reference data should also be relatively stable between the before and after periods. 


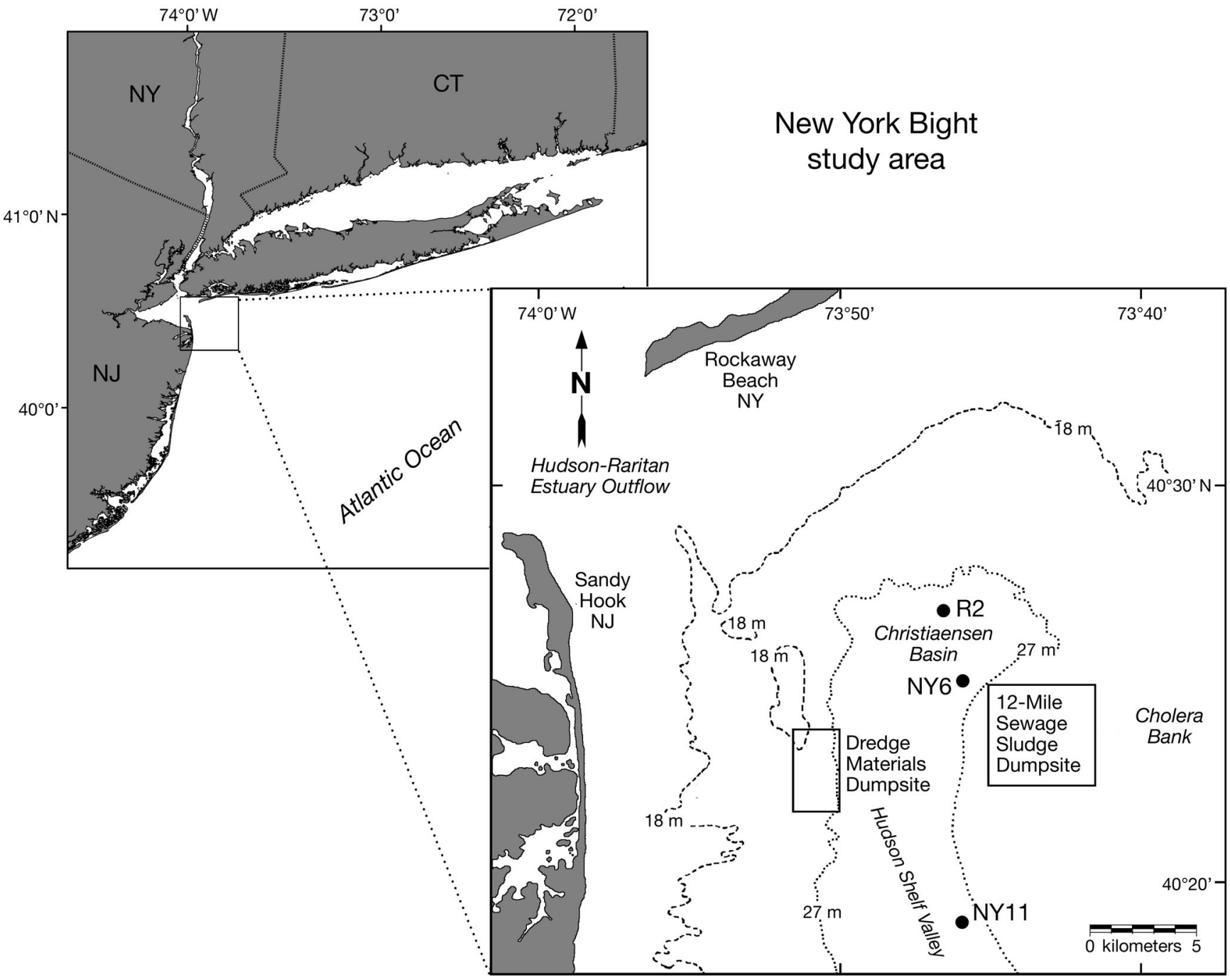

Fig. 1. New York Bight, showing the locations of the former 12-Mile Sewage Sludge Dumpsite and the 3 sampling sites (•) in the inner New York Bight study area

Because the 12MDSRS was not a typical impact study but addressed recovery from a long-term impact, the choice of appropriate study sites for use in a BACI analysis was not straightforward. No information was available about the macrofaunal assemblage that was present at a sludge impact site prior to disposal. The assemblage that would be present at a sludge impact site in the 21 mo after-cessation period was not known. Thus we could not be confident that any nearby site unaffected by sludge would be able to provide adequate reference abundance data for any of the taxa colonizing a sludge impact site. Also, it would most likely take many years for the contamination levels in the sediments at an impact site to become similar to the levels at a reference site unaffected by sludge. To increase the possible number of taxa that could be tested for sludge cessation effect, we chose 3 study sites: a highly contaminated sludge impact site, NY6; a reference site with minimal sludge influence, NY11; and an intermediate site, R2. All sites were located along the $30 \mathrm{~m}$ depth contour (EPD 1988; our Fig. 1, Table 1).

NY6 is located near the eastern margin of the Christiaensen Basin at a depth of $31 \mathrm{~m}$ and is $1.6 \mathrm{~km}$ downslope from the northwest corner of the designated dump site, the location where most sludge dumping occurred (EPD 1988; our Fig. 1). Historical data on sediment contaminant levels indicated that, of the 3 sampling sites, NY6 was most influenced by sewage sludge inputs (Table 1). The benthic macrofauna at this site were characterized by reduced species richness, low levels of abundance and biomass, and intermittently high abundances of Capitella spp. Diversity and abundance of crustaceans, especially amphipods, are low 
Table 1. Mean before and after cessation concentrations of sediment variables measured at NY6, NY11, and R2 during the 12MDSRS study from indicated sources

\begin{tabular}{|c|c|c|c|c|c|c|c|c|}
\hline \multirow[t]{2}{*}{ Sediment variable } & \multirow[t]{2}{*}{ Depth } & \multicolumn{2}{|c|}{- NY6 -} & \multicolumn{2}{|c|}{- NY11- } & \multicolumn{2}{|c|}{$\longrightarrow \mathrm{R} 2-$} & \multirow[t]{2}{*}{ Source } \\
\hline & & Before & After & Before & After & Before & After & \\
\hline Mean grain size $(\Phi)$ & $0-5 \mathrm{~cm}$ & 3.58 & 3.47 & 3.13 & 3.07 & 3.14 & 3.18 & Packer et al. 1995 \\
\hline Fines $(\%>4 \Phi)$ & $0-5 \mathrm{~cm}$ & 24.4 & 20.7 & 8.3 & 8.6 & 15.5 & 16.4 & Packer et al. 1995 \\
\hline TOC (\% weight) & $0-1 \mathrm{~cm}$ & 4.55 & 2.33 & 0.26 & 0.33 & 0.92 & 0.93 & Packer et al. 1995 \\
\hline Redox $(\mathrm{mV})$ & $0.5 \mathrm{~cm}$ & 87 & 218 & 245 & 286 & 205 & 244 & Draxler 1995 \\
\hline $\mathrm{Cr}\left(\mu g g^{-1}\right)$ & $0-1 \mathrm{~cm}$ & 163 & 96.5 & 15.8 & 12.9 & 37.2 & 36.7 & Zdanowicz et al. 1995 \\
\hline $\mathrm{Cu}\left(\mu \mathrm{g} \mathrm{g}^{-1}\right)$ & $0-1 \mathrm{~cm}$ & 312 & 151 & 10.9 & 6.74 & 38.6 & 37.5 & Zdanowicz et al. 1995 \\
\hline $\mathrm{Ni}\left(\mu \mathrm{g} \mathrm{g}^{-1}\right)$ & $0-1 \mathrm{~cm}$ & 29.5 & 16.9 & 5.81 & 4.67 & 8.58 & 8.32 & Zdanowicz et al. 1995 \\
\hline $\mathrm{Pb}\left(\mu \mathrm{g} \mathrm{g}^{-1}\right)$ & $0-1 \mathrm{~cm}$ & 272 & 153 & 22.5 & 19.3 & 56 & 54.3 & Zdanowicz et al. 1995 \\
\hline $\mathrm{Zn}\left(\mu \mathrm{g} \mathrm{g}^{-1}\right)$ & $0-1 \mathrm{~cm}$ & 532 & 232 & 32.7 & 26.4 & 83.9 & 79.6 & Zdanowicz et al. 1995 \\
\hline $\mathrm{Zn}\left(\mu \mathrm{g} \mathrm{g}^{-1}\right)$ & $4-5 \mathrm{~cm}$ & 289 & 288 & 35.2 & 34.9 & 147 & 147 & Zdanowicz et al. 1995 \\
\hline Tomato seeds (no. grab ${ }^{-1}$ ) & $0-10 \mathrm{~cm}$ & 984 & 1233 & 0.5 & 0.4 & 328 & 420 & Reid et al. 1995 \\
\hline
\end{tabular}

compared to other less stressed areas of the NY Bight (Steimle et al. 1982, Reid et al. 1991, Chang et al. 1992).

NY11 is located along the eastern shoulder of the upper Hudson Shelf Valley, $9.9 \mathrm{~km}$ south of where most of the dumping occurred. The depth of NY11 is $29 \mathrm{~m}$ (Fig. 1). Historical data indicated minimal influence by sludge dumping in the sediments at this site (Table 1). The macrofaunal species at NY11 are those typically found in silty very fine sands of the upper Hudson Shelf Valley (EPD 1988, Reid et al. 1991, Chang et al. 1992). The data from NY11 were used as reference data in the BACI analysis.

The intermediate site, R2, is located $3.4 \mathrm{~km} \mathrm{NNW}$ of the center of the sludge dump site at the northern edge of the Christiaensen Basin and at an average depth of $28.5 \mathrm{~m}$ (Fig. 1). The macrofauna at R2 were characterized as an enriched assemblage with high biomass of several species (Reid et al. 1991). Sediment contaminant levels (total organic carbon [TOC] and trace metals) were approximately $20 \%$ of those at the sludge impact site (Table 1). It was not known what percentages of the contaminants at R2 were from sewage sludge versus from other sources such as the HudsonRaritan Estuary (EPD 1988; our Fig. 1). The sediments at R2 also contained tomato seeds (Table 1), which are indicators of the heavier sludge fraction (Reid et al. 1995). Depending on the responses of the variables at R2 during the study, its data could be used as a second reference site or alternatively as an impact site with a lower level of sludge treatment. Data from the 12MDSRS (Table 1) indicated that contaminant levels in the sediments at $\mathrm{R} 2$ remained stable throughout the study compared to levels at NY6. Therefore, we used the data from R2 as reference data.

Field sampling and laboratory procedures. Three $0.1 \mathrm{~m}^{2}$ Smith-McIntyre benthic grab samples were taken each month at each of the 3 study sites for 18 mo during phased cessation of sludge dumping (July 1986-December 1987) and for 21 mo after sludge dumping ended (January 1988-September 1989) for a total of 39 monthly sampling events. This was considerably higher-frequency sampling both before and after termination of sludge disposal than had been conducted in other sewage sludge recovery studies (Moore \& Rodger 1991, Dorsey et al. 1995). Samples from grabs penetrating the sea floor a minimum of $6 \mathrm{~cm}$ and showing a relatively undisturbed surface were accepted. Otter trawl samples were also taken at each site to assess demersal fish abundance (Pikanowski 1992) and food habits (Stehlik 1993, Steimle et al. 1994). Loran C navigation, with nominal accuracy of $\pm 50 \mathrm{~m}$, was used for sample site relocation. The 3 sites were sampled within a consecutive $3 \mathrm{~d}$ period during most months; this sampling is considered simultaneous for the purposes of data analysis (EPD 1988).

Each grab sample included in situ vertical probe measurements of sediment redox potential $\left(\mathrm{E}_{\mathrm{H}}\right)$. Core subsamples were also taken from each grab to determine sediment grain size and the concentrations of sediment trace metals and TOC (Draxler 1995, Packer et al. 1995, Zdanowicz et al. 1995). The remaining sediment in each grab sample was washed through a $0.5 \mathrm{~mm}$ stainless steel sieve. Retained materials were removed and fixed in $10 \%$ buffered formalin and seawater solution with rose bengal biological stain added to aid in sorting out the biological material. Within $72 \mathrm{~h}$, the samples were transferred to a $70 \%$ ethanol and $5 \%$ glycerin solution. In the laboratory, samples were sorted under a dissecting microscope, and the invertebrates were removed, counted, and identified to species level where possible. Wet weight biomasses were determined for each species in a sample by blot-drying the species collections on absorbent paper towels for about $3 \mathrm{~min}$ and weighing them to the nearest $\mathrm{mg}$. 
Statistical analysis. The BACI design of StewartOaten et al. (1986) modified for this study by Pikanowski (1992) was used to test the responses of individual species to cessation at NY6. The average monthly abundance for a given species at NY6 was used as a statistical replicate. Prior to statistical testing, a co-variable was subtracted from each monthly replicate at NY6 in an attempt to account for background variability not associated with cessation of sludge disposal (Stewart-Oaten \& Bence 2001). The co-variable used was the average abundance for the same species during the corresponding month at a reference site. This yielded 18 adjusted abundance replicates prior to cessation to compare with 21 adjusted abundance replicates after cessation for each species tested. We performed 2 separate analyses, 1 using the data at NY11 as a co-variable and the other using data from R2 as a co-variable. We tested the difference in adjusted mean abundance between the before- and after-cessation study periods for each species using the parametric Student's $t$-test. If our data violated the normality and equal variance assumptions of the $t$-test, we used the non-parametric MannWhitney $U$-test.

Non-additivity and serial correlation can confound results of the BACI analysis (Stewart-Oaten et al. 1986, Pikanowski 1992). Serial correlation indicates that the replicates in time are not independent. One of the functions of abundance data from the reference site is to balance the effect of serial correlation in the adjusted replicates. However, if abundance data over time at impact and reference sites do not fluctuate in synchrony (track), serial correlation can occur in the adjusted replicates. We therefore tested the monthly adjusted replicates for serial correlation using the parametric (c) or the non parametric (runs) tests. Valid interpretation of the statistical results can be made based on the type of the serial correlation, the period (before or after cessation) it occurred, and the ability of $\log$ transformation to reduce its effect. It is expected that reduction of sludge contaminants in the sediments after cessation may cause trends (serial correlation) in the data for some variables during the after period (Pikanowski 1992).

PRIMER software (Plymouth Marine Laboratory, UK) was used to follow changes in community structure over time at the 3 sites. A similarity matrix based on the Bray-Curtis coefficients was generated using [ln $(1+\mathrm{x})$ ]-transformed average abundance data for all species present at each site and sampling month. Abundance data were transformed to reduce the effect of dominant species on the Bray-Curtis similarity measure. A non-metric, multidimensional scaling (MDS) ordination (Clarke 1993) was constructed using the similarity matrix. The MDS ordination is the best 2-dimensional fit displaying differences in faunal similarity among sites and sampling months. For this study, there were 117 points on the plot ( 3 sites $\times 39 \mathrm{mo}$ ).

To examine factors that may be important to the recovery of benthic macrofauna at NY6, we used the BIO-ENV program of PRIMER (Clarke \& Ainsworth 1993) to determine which combination of sediment quality variables (Table 1) was most strongly related to the macrofaunal ordination. We also used the bubble plot feature of PRIMER to superimpose the relative concentrations of sludge indicators in the sediments as circles of different sizes onto the corresponding site and sampling month on the macrofaunal ordination. The bubble plot feature allowed visualization of simultaneous changes in macrofaunal community structure and concentrations of sludge indicators in the sediments over time.

\section{RESULTS}

\section{Macrofaunal abundance and biomass}

A total of 245 benthic macroinvertebrate taxa were identified at the 3 study sites. The little nut clam Nucula proxima was numerically dominant over the entire study and was most abundant at reference site NY11 (Fig. 2a-c). Reference site R2 had the greatest biomass both before and after cessation (Table 2). The large biomasses of Arctica islandica at NY11 and R2 in the before period was due to 2 large individuals found in the grabs at both sites (J. J. Vitaliano pers. obs.). Although Capitella spp. were the numerically dominant taxa prior to cessation at the sludge impact site, NY6, monthly densities varied considerably in the before period (Fig. 3).

\section{BACI analysis of the responses of individual species}

The BACI analysis (Table 3) indicated significant sludge cessation effect for Spiophanes bombyx (Fig. 4a), Sthenelais limicola, Photis pollex, Cerastoderma pinnulatum, and Pitar morrhuanus (Fig. 4b) using data from both reference sites, NY11 and R2, as a co-variable, Arctica islandica, Unciola irrorata, and Dyopedos monacanthus using data from NY11 as a covariable, and Spio setosa and Phoronis architecta using data from R2 as a co-variable.

\section{MDS plot}

The MDS ordination showed that community structure at the impact site, NY6, was more variable among 

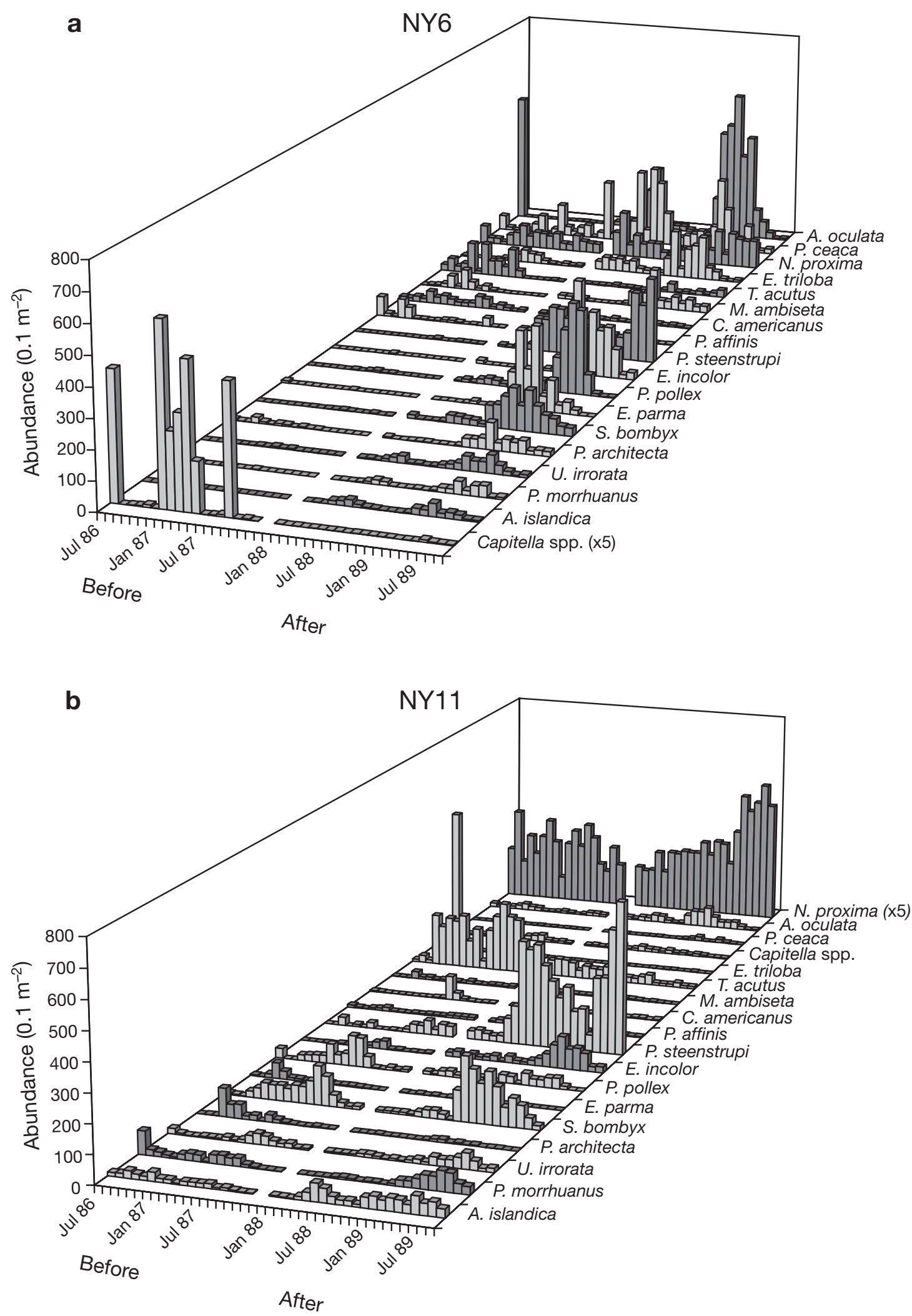

Fig. 2. (Above and facing page) Mean monthly abundances $\left(0.1 \mathrm{~m}^{-2}\right)$ for the numerically-dominant benthic macroinvertebrate species over 39 mo from the 12MDSRS (a) impact site, NY6; (b) reference site, NY11; and (c) reference site, R2. See Table 3 for full names of species 


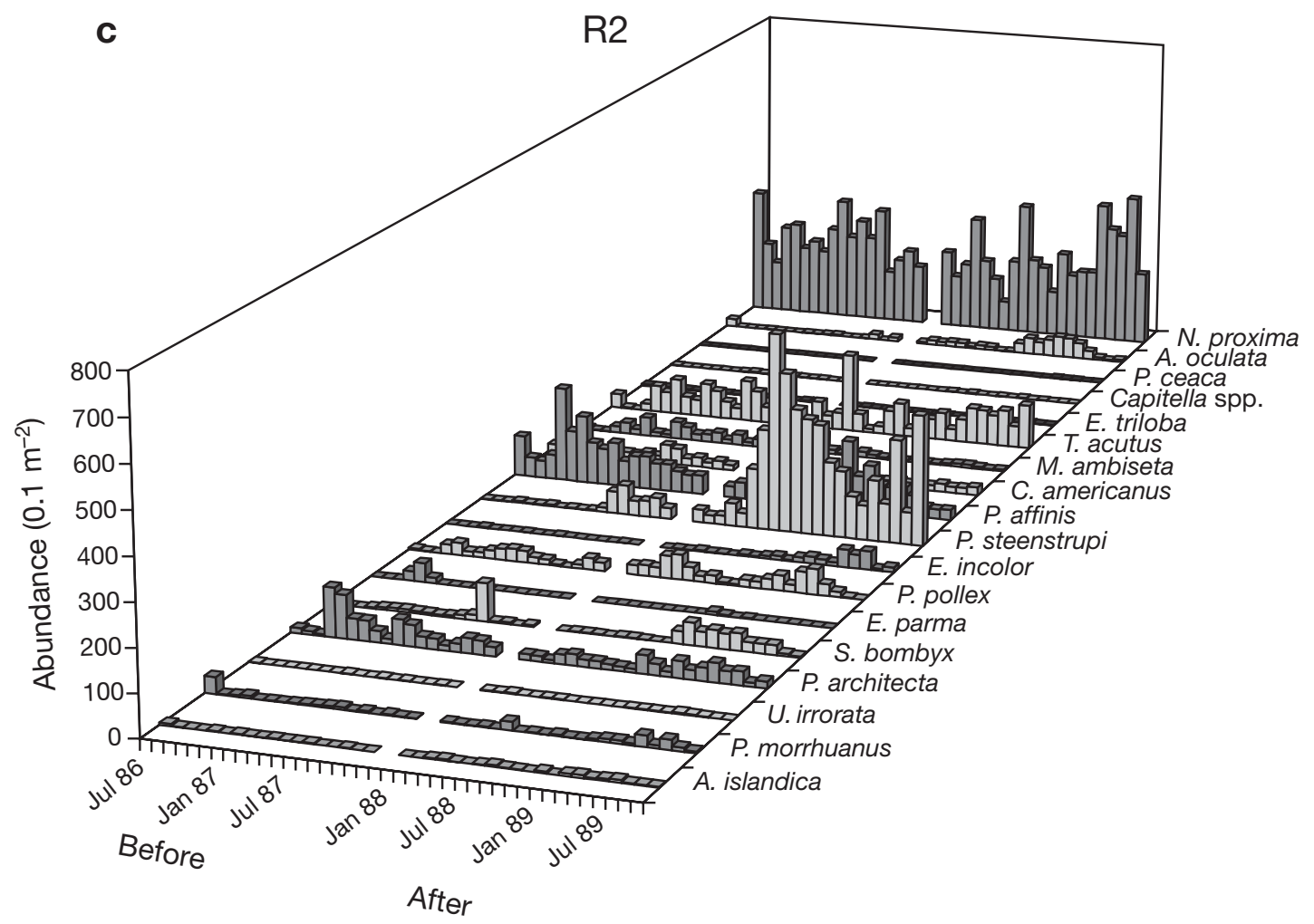

Fig. 2 (continued)

Table 2. Mean before and after cessation biomasses mg $\left(0.1 \mathrm{~m}^{-2}\right)$ of the 12 biomass-dominant taxa at NY6, NY11, and R2

\begin{tabular}{|c|c|c|c|c|c|c|}
\hline \multirow[t]{2}{*}{ Taxa } & \multicolumn{2}{|c|}{ - NY6 } & \multicolumn{2}{|c|}{ NY11 } & \multirow{2}{*}{$\overline{\text { Before }}$} & \multirow[b]{2}{*}{ After } \\
\hline & Before & After & Before & After & & \\
\hline Ceriantheopsis americanus & 917.6 & 612.3 & 806.7 & 651.6 & 1898.5 & 1809.0 \\
\hline Nemertea sp. & 2875.8 & 922.4 & 233.8 & 224.2 & 334.3 & 488.8 \\
\hline Nephtys incisa & 281.0 & 47.9 & 88.3 & 86.6 & 1761.3 & 1058.4 \\
\hline Glycera dibranchiata & 10.9 & 32.9 & 377.8 & 316.0 & 7.6 & 0.3 \\
\hline Scoletoma acicularum & 4.6 & 4.3 & 358.3 & 420.6 & 0.0 & 0.0 \\
\hline Ninoe nigripes & 2.0 & 13.2 & 123.7 & 184.3 & 183.9 & 91.4 \\
\hline Pherusa affinis & 187.4 & 232.6 & 1232.3 & 1282.5 & 15673.0 & 12632.8 \\
\hline Capitella spp. & 1450.7 & 3.6 & 14.3 & 2.7 & 0.3 & 0.1 \\
\hline Nucula proxima & 110.7 & 54.2 & 724.2 & 722.1 & 134.9 & 144.9 \\
\hline Arctica islandica & 0.7 & 8.3 & 8168.8 & 83.3 & 1813.8 & 5.6 \\
\hline Pitar morrhuanus & 6.8 & 4.9 & 1199.9 & 1236.3 & 9845.8 & 10845.8 \\
\hline Ensis directus & 0.1 & 0.3 & 0.3 & 0.4 & 306.5 & 1036.6 \\
\hline Total biomass & 6343.0 & 2836.0 & 16029.0 & 8640.6 & 33474.8 & 31129.0 \\
\hline
\end{tabular}

months. Community structure at the reference sites remained fairly stable (Fig. 5a). At NY6 there was an obvious separation between the before-cessation and after-cessation data. The community structure of the August, September, and October 1986 samples (Months 2, 3, 4) and July, August, and September 1987 samples (Months 13, 14, 15) at NY6 prior to cessation were most dissimilar to the other months at NY6, with Months 13, 14, and 15 being the most dissimilar to any of the months at NY11 and R2 (Fig. 5a). Both the MDS ordination (Fig. 5a) and plots of the Bray-Curtis similarity coefficients between NY6 and NY11 and between NY6 and R2 (Fig. 6) indicated that community structure at NY6 was steadily becoming more similar to that at both reference sites following cessation. The stress value for the MDS plot was 0.13 and was acceptable considering the large number of samples used in the analysis (see Clarke 1993). 

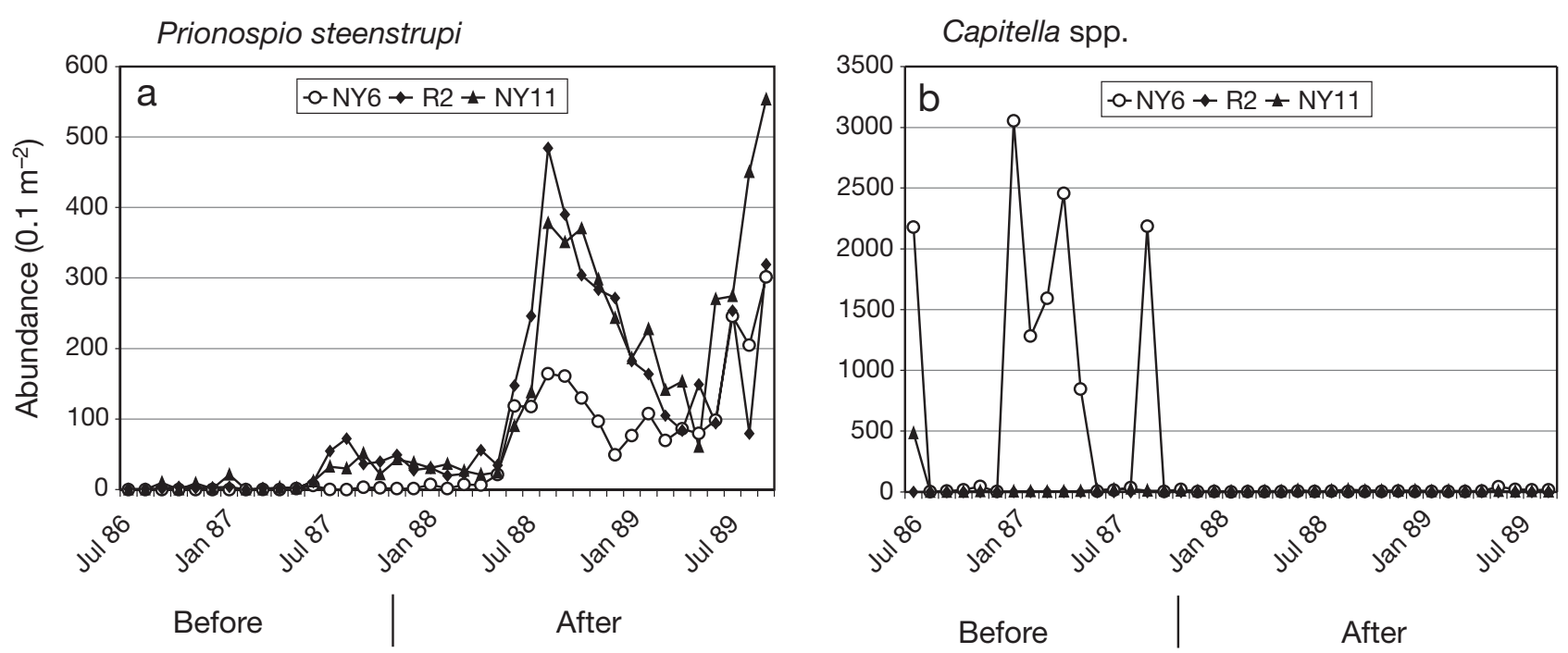

Fig. 3. Mean monthly abundances $\left(0.1 \mathrm{~m}^{-2}\right)$ at NY6, NY11, and R2 for (a) Prionospio steenstrupi and (b) Capitella spp.

Table 3. Raw mean difference in abundance (After minus Before) at the impact site (NY6), adjusted mean difference in abundance (After minus Before) at NY6 (calculated separately using reference data from NY11 or R2 as a covariable). *Significant difference at impact site after log transformation using either the $t$-test or Mann-Whitney $U$-test performed on the adjusted replicates in time; X: abundances over time not sufficient at reference site to run statistical tests

\begin{tabular}{|lrcc|}
\hline \multirow{2}{*}{ Species } & \multirow{2}{*}{ Raw } & \multicolumn{2}{c|}{ Adjusted data } \\
\cline { 4 - 4 } & & $\mathrm{NY} 11$ & $\mathrm{R} 2$ \\
\hline Capitella spp. & -756.6 & $\mathrm{X}$ & $\mathrm{X}$ \\
Asabellides oculata & 113.4 & $\mathrm{X}$ & $\mathrm{X}$ \\
Prionospio steenstrupi & 101.5 & $\mathrm{X}$ & $\mathrm{X}$ \\
Euchone incolor & 64.8 & $\mathrm{X}$ & $\mathrm{X}$ \\
Parougia caeca & 60.5 & $\mathrm{X}$ & $\mathrm{X}$ \\
Photis pollex & 57.9 & $72.8^{*}$ & $48.1^{*}$ \\
Echinarachnius parma & 52.0 & $\mathrm{X}$ & $\mathrm{X}$ \\
Spiophanes bombyx & 48.8 & $26.4^{*}$ & $42.7^{*}$ \\
Edotia triloba & 39.3 & $\mathrm{X}$ & $\mathrm{X}$ \\
Nucula proxima & 29.8 & $\mathrm{X}$ & 26.9 \\
Tharyx acutus & -29.4 & $\mathrm{X}$ & -37.9 \\
Unciola irrorata & 16.4 & $13.3^{*}$ & $\mathrm{X}$ \\
Phoronis architecta & 15.9 & $\mathrm{X}$ & $31.4^{*}$ \\
Ceriantheopsis americanus & -14.0 & -8.4 & -9.0 \\
Mediomastus ambiseta & 13.2 & 14.8 & 22.4 \\
Arctica islandica & 10.6 & $-6.7^{*}$ & $\mathrm{X}$ \\
Pherusa affinis & -10.5 & -9.9 & -20.2 \\
Pitar morrhuanus & 10.3 & $5.6^{*}$ & $6.7^{*}$ \\
Tellina agilis & -8.3 & $\mathrm{X}$ & $\mathrm{X}$ \\
Nemertea sp. & -7.3 & -5.3 & -4.7 \\
Dyopedos monacanthus & 6.9 & $6.4^{*}$ & 4.8 \\
Cerastoderma pinnulatum & 5.6 & $5.0^{*}$ & $4.8^{*}$ \\
Spio setosa & 4.5 & -40.3 & $6.3^{*}$ \\
Phyllodoce mucosa & 4.4 & $\mathrm{X}$ & $\mathrm{X}$ \\
Sthenelais limicola & 3.0 & $2.4^{*}$ & $2.8^{*}$ \\
Nephtys incisa & -2.5 & -2.4 & -3.3 \\
Ninoe nigripes & 2.0 & $\mathrm{X}$ & 0.7 \\
Leptocheirus pinguis & 1.1 & $\mathrm{X}$ & $\mathrm{X}$ \\
& & & \\
\hline
\end{tabular}

\section{BIO-ENV results}

Results of BIO-ENV analysis indicated that the highest correlation coefficient between the MDS ordination and a single sediment quality variable at NY6 (Table 4) was with redox potential $(\mathrm{r}=0.407)$. The highest correlation coefficient for a combination of sediment quality variables was with redox potential, zinc, and TOC ( $\mathrm{r}=$ 0.451).

\section{Bubble plots of superimposed variables}

Sediments at NY6 were most influenced by sludgerelated indicators as shown by bubble plots of sediment redox potential at the $0.5 \mathrm{~cm}$ sediment layer (Fig. $5 \mathrm{~b}$ ) and for concentrations of zinc (Fig. 5c) and TOC (Fig. 5d) in the 0-1 cm sediment layer. The study-wide reduction in concentrations of TOC and zinc and increase in redox potential after cessation (Draxler 1995, Packer et al. 1995, Zdanowicz et al. 1995) correspond to shifts in macrofaunal community structure at NY6 (Fig. 5a). Concentrations of zinc and TOC at NY11 and $\mathrm{R} 2$ remained stable over time (little change in circle diameters; Fig. 5c,d and Table 1).

\section{DISCUSSION}

Responses to cessation of sewage sludge disposal at our most contaminated site were rapid for many benthic macrofaunal measures (Figs. 2a \& 3-6) despite the fact that sewage sludge had been affecting the area for $60 \mathrm{yr}$. The BACI analysis showed sludge cessation effect for 10 taxa that included a number of 

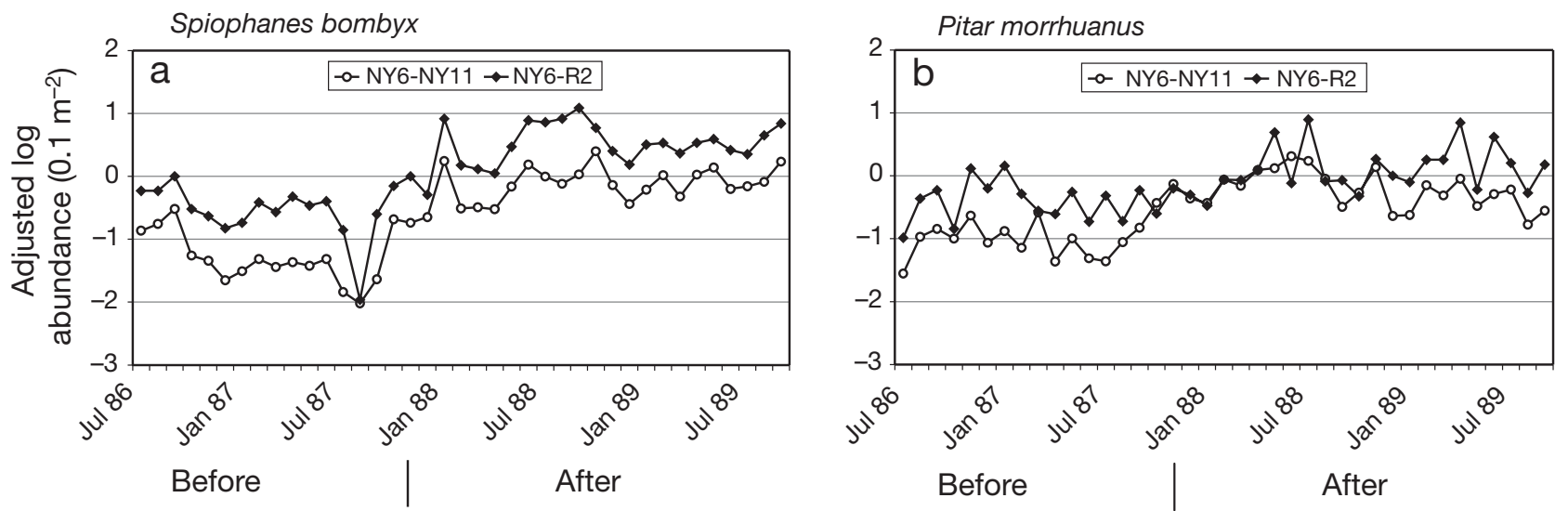

Fig. 4. Mean monthly log-transformed adjusted abundance data (NY6-NY11 and NY6-R2) for (a) Spiophanes bombyx and (b) Pitar morrhuanus

MDS of Bray-Curtis similarities

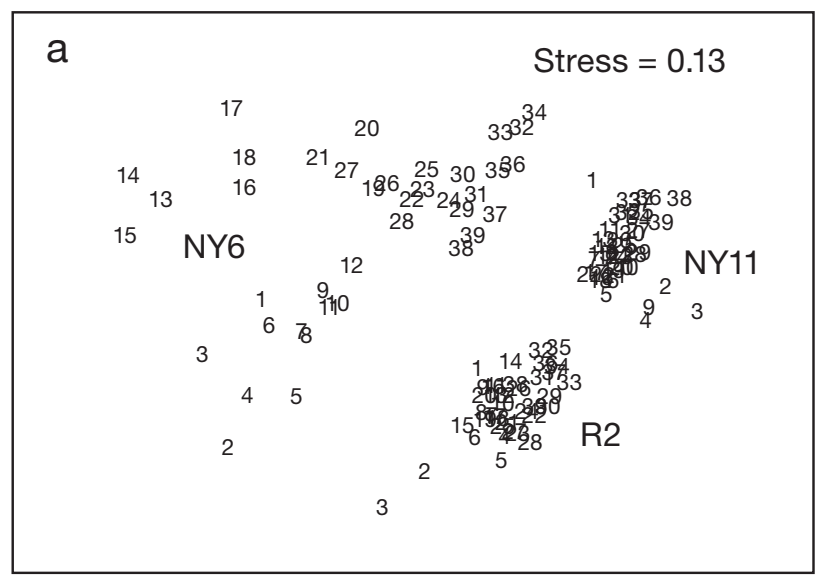

Sediment zinc concentrations

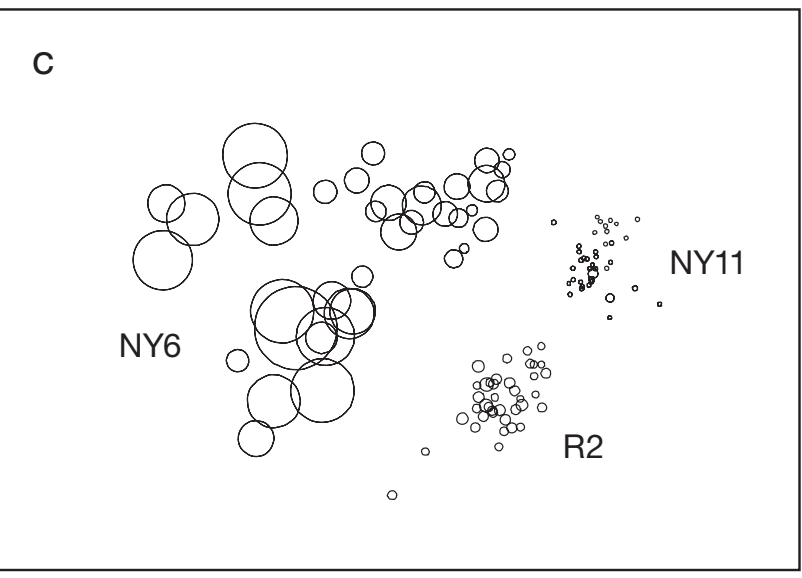

Sediment $\mathrm{E}_{\mathrm{H}}$

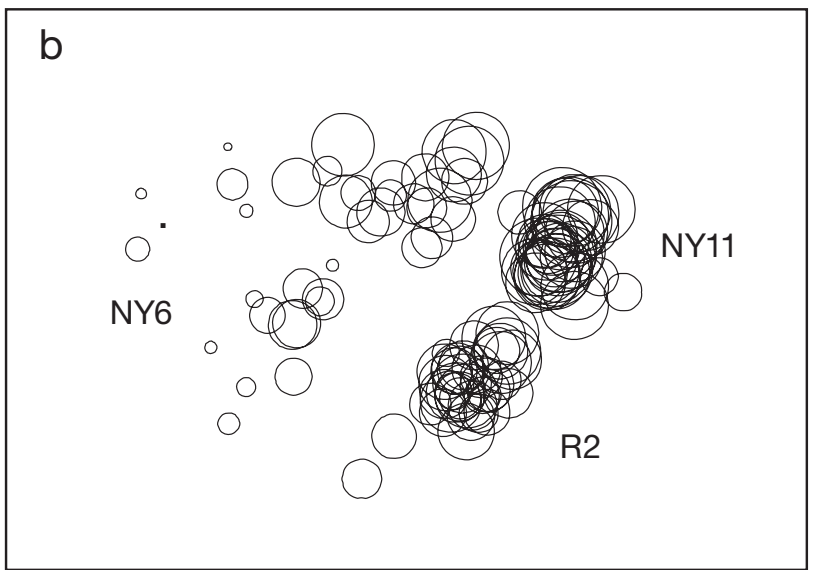

Sediment TOC concentrations

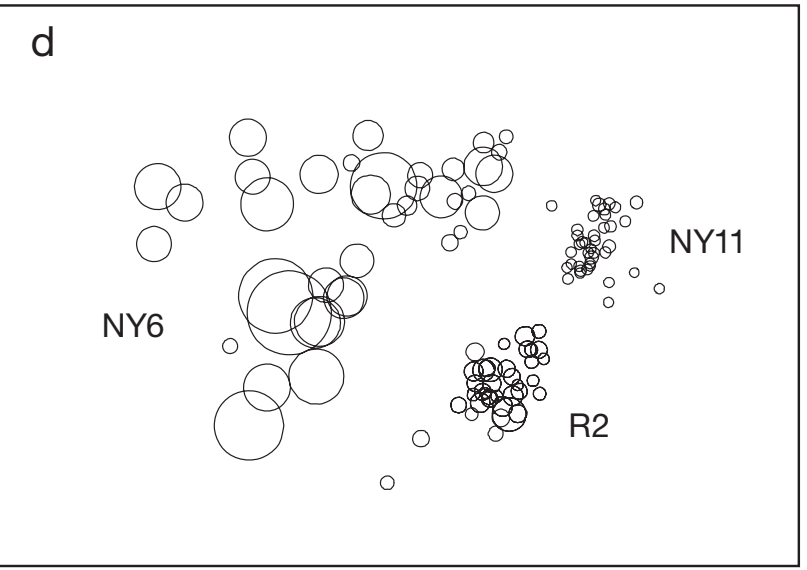

Fig. 5. (a) MDS plot comparing the macrofaunal similarities among NY6, NY11, and R2 for each month of the 12MDSRS. The positions on the ordination for each consecutive sampling month at each site are denoted by the numbers 1 to 39. (b-d) Bubble plots showing the relative monthly values for $(\mathrm{b})$ redox potential $\left(\mathrm{E}_{\mathrm{H}}\right)$ at the $0.5 \mathrm{~cm}$ sediment depth layer; (c) zinc concentrations $\left(\mu \mathrm{g} \mathrm{g}^{-1}\right.$ ) in the $0-1 \mathrm{~cm}$ sediment layer, and (d) percent total organic carbon (TOC) in the $0-1 \mathrm{~cm}$ sediment layer that have been superimposed onto the corresponding month of the macrofaunal ordination in Fig. 5a. Redox data from Draxler (1995), TOC data from Packer et al. (1995), zinc data from Zdanowicz et al. (1995) 


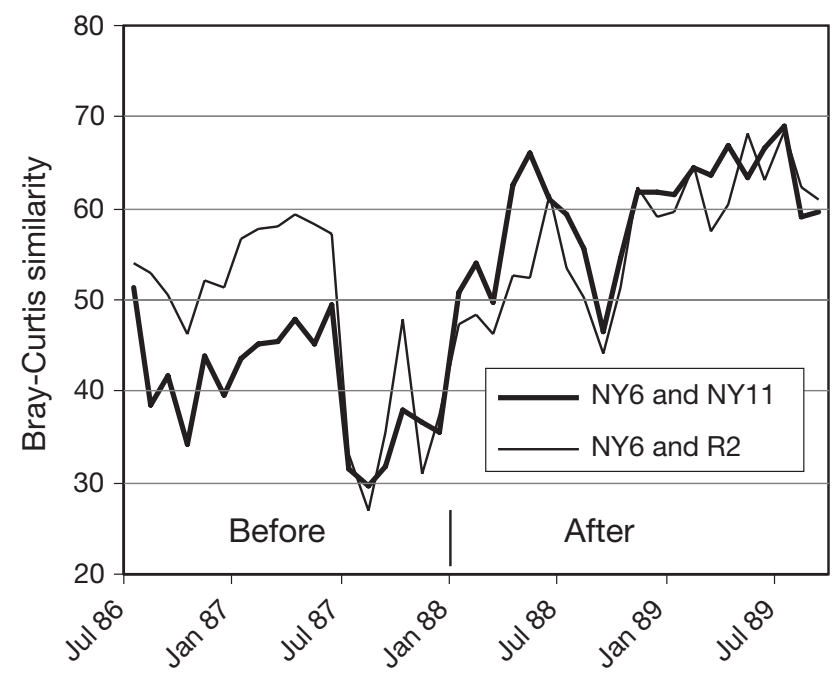

Fig. 6. Plots of the monthly Bray-Curtis similarities between NY6 and NY11 and between NY6 and R2 for the 39 mo of the 12MDSRS

Table 4. Results of the BIO-ENV procedure used to select sediment variables associated with the community structure patterns at NY6. The $\mathrm{r}$ value is given for the individual sediment variables and for the best 2 and 3 variable combinations

\begin{tabular}{|cc|}
\hline \multicolumn{2}{|c|}{ BIO-ENV Results } \\
$\mathrm{r}$ & Sludge indicator \\
\hline 0.407 & Redox \\
0.217 & $\mathrm{Zn}$ \\
0.195 & $\mathrm{Cu}$ \\
0.177 & $\mathrm{~Pb}$ \\
0.158 & $\mathrm{TOC}$ \\
0.073 & $\mathrm{Cr}$ \\
0.442 & Redox, $\mathrm{Zn}$ \\
0.451 & Redox, Zn,TOC \\
\hline
\end{tabular}

amphipod and mollusk species (Table 3). An overall indicator of cessation of sewage sludge disposal at the 12MDS was the shift observed in benthic macrofaunal community structure (Fig. 5a) at NY6, as well as the increased Bray-Curtis similarity coefficient between NY6 and both reference sites (Fig. 6). Multivariate community analysis is an integration of the responses of many taxa and has the advantage of enhancing the response signal compared to individual species analysis (Clarke 1993).

Our results confirm the difficulties identified a priori about the data from reference sites needed to run a valid BACI analysis (Stewart-Oaten et al. 1986, Pikanowski 1992). Therefore, some taxa showing large differences in abundance after cessation at the impact site such as Prionospio steenstrupi (Fig. 3a), Capitella spp. (Fig. 3b), Euchone incolor, and Echinarachnius parma (Fig. 2) could not be statistically tested for sludge cessation effect (Table 3 ). There were inadequate abundance data at either reference site to factor out the effects of background variability at the impact site. For example, there were large increases in the mean abundances of P. steenstrupi (Fig. 3a) at all 3 sites in the after-cessation period. Because abundances of $P$. steenstrupi were inadequate (low) in the before period and not stable between the before and after periods at either reference site, it could not be determined if the increases at the impacted site, NY6, was due to cessation of sludge dumping or background factors, such as the unavailability of larvae at all 3 sites in the before-cessation period. Other sites along the 30 $\mathrm{m}$ depth contour in the inner NY Bight may have provided reference abundance data for some of these species. Despite our inability to perform a valid BACI analysis on the responses of Capitella spp., the large decrease in the mean abundance at NY6 in the aftercessation period (Fig. 3b) was most likely an effect of cessation of sludge dumping. It has been well documented that large numbers of Capitella spp. are an indicator of organic enrichment in marine sediments (Pearson \& Rosenberg 1978).

The intent of 12MDSRS was to synoptically measure the responses to cessation of as many ecosystem variables as possible. These included sediment quality, fish abundance and biomass, and benthic macroinvertebrate abundances. Due to differences in variance and effect size, sampling requirements were different for each variable. Because of the short duration of the 12MDS study and the need to provide as many replicates as possible before and after cessation for the statistical comparisons for each variable, we decided on a monthly sampling frequency (Pikanowski 1992). High frequency sampling as well as asynchronous data between reference and impact sites were responsible for serial correlation found in the adjusted abundance data for macrofauna. We were able to validate a sludge cessation effect for 10 species following log-transformation and confirmation that there were no periodwide trends in the temporal abundance data during the before period (Table 3, Fig. 4 and see StewartOaten et al. 1986, Pikanowski 1992). Sediment quality data and trawl data from the 12MDSRS did not exhibit serial correlation (Pikanowski 1992, Packer et al. 1995, Zdanowicz et al. 1995).

There have been numerous clarifications and modifications of the BACI designs, and there is no consensus about the necessity of using more than one reference site (Underwood 1991, Humphrey et al. 1995, Hewitt et al. 2001, Stewart-Oaten \& Bence 2001, Underwood \& Chapman 2003). In our study, we sampled 2 reference sites: a minimal sludge-influenced site, NY11, and an 
intermediate site, R2. Although there were differences in concentrations of sludge indicators in the sediments between the 2 sites, concentrations of these indicators remained stable over the entire study at both sites (Table 1, Fig. 5b-d). Therefore, the responses of the species at the impact site were tested separately using the corresponding abundance data for that species from each reference site as a co-variable (albeit at a different level of reference). Of the 10 species at our impact site showing a significant sludge cessation effect, 5 species were confirmed separately using reference data from both NY11 and R2 (Table 3). The results for the other 5 species, Spio setosa, Phononis architecta, Arctica islandica, Unciola irrorata, and Dyopedos monacanthus, were not as strong. All 5 species showed a significant sludge cessation effect based on data from only 1 reference site.

Physical oceanographic factors near the 12MDS (Manning et al. 1994, Davis et al. 1995, Mountain \& Arlen 1995, Packer et al. 1995) may have intermittently altered the presence of sludge and its effect on the biota. For example, in the summer months, higher water temperatures resulted in water mass stratification; in addition to reduced wave and current activity, this increased the possibility of accumulation of sludge contaminants. The interactions of the various sludge components as well as background physical and biological variables (see Clarke \& Ainsworth 1993) near 12MDS may explain the high degree of variability in community structure at the sludge impact site (Fig. 5a), especially during dumping, and may also explain our inability to detect strong associations between macrofaunal community structure and indicators of sludge in sediments (Table 4). A study near a sewage outfall on the US Pacific coast also found that relationships between macrofaunal community structure and sediment quality are not highly correlated. The fluctuations in community structure in that study are thought to be a result of natural events, such as winter storms and El Niño, as well as changes in contaminant input (Zmarzly et al. 1994).

In the 12MDSRS there was no evidence linking reduction in sludge inputs during the before period (phase-out) to the variability in community structure and sediment quality at NY6 (Fig. 5a-d). Significant reductions in trace metal concentrations were not found in the before period (Zdanowicz et al. 1995). Redox potentials in surface sediments at NY6 were lowest (Fig. 5b) during the summer months in the before-cessation period (Draxler 1995). Community structure at NY6 was most dissimilar to that of the reference sites in the summer just prior to complete cessation (Figs. 5a \& 6).

The rapid improvements in surface sediment quality at NY6 after cessation (Fig. 5b-d, Table 1) may be due not only to the elimination of contaminant input from sewage sludge, but also to rapid degradation of organic sludge components (Nedwell \& Lawson 1990), the nature of bottom currents in the vicinity of NY6 (Manning et al. 1994, Packer et al. 1995, Zdanowicz et al. 1995), and the relief associated with bottom topographic features such as the Hudson Shelf Valley (Fig. 1). Most of the taxa that increased in abundance on the cleaner surface sediments at NY6 after cessation (Fig. 2a) were typical of silty fine sand habitats of the inner NY Bight (Caracciolo \& Steimle 1983, Reid et al. 1991, Chang et al. 1992). These species apparently have life cycle characteristics that enable them to rapidly colonize a site once conditions become favorable for their survival (Pearson \& Rosenberg 1978, Zajac \& Whitlatch 1982, Caspers 1987).

The recovery of macrofauna at NY6 may have been influenced by the presence of large numbers of the tube-building polychaete Asabellides oculata (Fig. 2a). The opportunistic A. oculata builds mud tubes, known locally as 'spaghetti mud,' that extend well above the sediment surface (Caracciolo \& Steimle 1983). The presence of these tubes may have enhanced the recruitment and survival of the large abundances of juvenile (J. J. Vitaliano pers. obs.) sand dollars, Echinarachnius parma (Fig. 2a) as well as other invertebrates, that appeared at NY6 after cessation (sensu Gallagher et al. 1983, Schaffner 1990). Increased predation as a result of termination of sludge disposal may also have affected recovery. A benthic predator, winter flounder, increased in abundance at NY6 after cessation (Pikanowski 1992). At the same time, there was an increased frequency of occurrence of the benthic amphipod Unciola irrorata in stomachs of winter flounder at NY6 (Steimle et al. 1994). This corresponds to the time when the abundances of $U$. irrorata were increasing in the sediments at NY6 (Fig. 2a). In field studies, however, quantitative links between macrofauna and benthic predators are difficult to establish due in part to predator mobility and differences in the scale of the sampling devices (grab and trawl; Stehlik 1993, Steimle et al. 1994).

The numbers and biomasses of deeper burrowing, longer lived species such as Glycera dibranchiata, Ninoe nigripes, Pherusa affinis, Ceriantheopsis americanus, Nephtys incisa, and Pitar morrhuanus at NY6 did not approach the numbers and biomasses for these species at NY11 or R2 during the 21 mo aftercessation period (Fig. 2a-c, Table 2). Since many of these species have slow growth rates, sampling over a longer time period would be required to determine if the extent of recovery may have been affected by the reservoir of sewage sludge components in the deeper sediments remaining after cessation (Table 1 , Fig. $5 \mathrm{~b}-\mathrm{d}$ ). Trace metal concentrations in the $4-5 \mathrm{~cm}$ 
sediment layer at NY6 did not decrease in the after period (Zdanowicz et al. 1995). Also, sludge detritus was observed in the deeper sediment layers in all grab samples taken at NY6 in the after-cessation period (J. J. Vitaliano pers. obs.).

Direct comparisons of the responses documented in the 12MDSRS to those of the few other studies that have measured recovery following termination of sewage sludge disposal are difficult due to differences in site characteristics, amount and duration of dumping, and study design. Moore \& Rodger (1991) sampled a sewage sludge dump site in the Firth of Clyde (Scotland) $11 \mathrm{yr}$ after cessation. Their results indicate that macrofaunal measures near the dump site showed substantial differences compared to these same measures taken during active dumping and were considered normal for this slightly enriched area. Near the 7-mile Hyperion treatment plant outfall in Santa Monica Bay, California, recovery appeared to be progressing much slower compared to 12MDS in the NY Bight. Sites near the outfall continue to show substantial numbers of Capitella spp. 2 yr after cessation of sludge discharge, and after $5 \mathrm{yr}$, macrofaunal assemblages shifted from degraded to early transitional (Dorsey et al. 1995). In our study, once sludge dumping ended, Capitella spp. did not appear in large numbers at the sludge impact site (Figs. 2a \& 3b). Also in our study, community structure at the sludge impact site was approaching that at both reference sites $21 \mathrm{mo}$ after cessation (Figs. 5a \& 6). Limited data from semiannual surveys from 1991 to 1995 indicated that the community structure (Draxler et al. 1996) and biomass (J. J. Vitaliano unpubl. data) at NY6 were becoming very similar to that at our minimal sludge-influenced reference site, NY11, 7 yr after cessation.

The results of the 12MDSRS partially followed P\&R. As predicted by the model, there was an increase in the numbers of species (Reid et al. 1995) and a decrease in the abundances of Capitella spp. (Fig. 3b) at NY6 following termination of disposal at the 12MDS. However, during the time course of the study, azoic conditions were not found at our most contaminated study site, NY6. Dissolved oxygen (DO) levels in the water, $0.1 \mathrm{~m}$ above the bottom at NY6 never fell below $2 \mathrm{mg} \mathrm{l}^{-1}$ (L. Arlen unpubl. data). At the beginning of the study, the site we chose as an intermediate site, R2, appeared to have biological and sediment characteristics similar to that of a transitional site in P\&R. However, macrofaunal community structure and sediment contaminant levels remained stable throughout the study (Packer et al. 1995, Zdanowicz et al. 1995; Table 1, Fig. 5a-d).

The specific characteristics of the 12MDSRS study sites as well as the overall oceanographic conditions within the inner NY Bight may explain differences observed between the responses of the macrofauna during the 12MDSRS and P\&R. 12MDSRS oceanographic data indicate equilibrium between erosional and depositional events at our 3 study sites with little net accumulation of sediments (Bopp et al. 1995, Davis et al. 1995, Packer et al. 1995). These oceanographic characteristics are in contrast to the depositional sites used to develop P\&R and are more similar to open coastal sites discussed in Maurer et al. (1993). Oceanographic events may have also masked the effects of cessation of sludge disposal at our intermediate site, R2. Episodic up-valley flow events (Manning et al. 1994) may have transported contaminated resuspended material from the vicinity of NY6 and the upper Hudson Shelf Valley towards R2 at the edge of the Christiaensen Basin after cessation. It is also likely that R2 was influenced by contaminant input from the outflow of the Hudson-Raritan estuary (EPD 1988, Zdanowicz et al. 1995). The responses of the benthic macrofauna from sites within the deeper, more quiescent, Hudson Shelf Valley (Fig. 1) which most likely were receiving sludge input during dumping may have followed P\&R more precisely.

The results of the 12MDSRS demonstrate the difficulty involved in detecting effects of human impacts (sewage sludge in this study) on benthic ecosystem measures. Our results have implications for future BACI studies attempting to determine the effects of other human impacts (e.g. oil and gas exploration, dredge spoils disposal, sand mining, fishing gear, and waste discharges) on essential fish habitats and other important marine ecosystem components. The BACI design we used (Stewart-Oaten et al. 1986, Pikanowski 1992) was able to show a significant sludge cessation effect for only some of the species that became established at the sludge impact site after cessation (Table 3). For other species, there was a lack of before and after abundance data at the reference sites to factor out the effects of background variability from the effects of sludge cessation. Since all BACI designs have their specific difficulties in determining significant impact, Hewitt et al. (2001) suggested that versatile sampling strategies be used in impact studies so that a number of BACI designs can be attempted. The 12MDSRS was multidisciplinary and had the advantage of measuring many variables including sediment quality. We not only used a BACI design but also a number of multivariate data analysis techniques. MDS analyses and the corresponding bubble plots showed clear differences in benthic community structure and sediment quality at our most contaminated site following termination of sludge disposal (Fig. 5). These features of the 12MDSRS complemented each other to demonstrate the effects of sludge disposal and recovery of the benthic habitats near the former 12MDS. 
Acknowledgements. We thank the many members of the Ecosystems Processes Division, Northeast Fisheries Science Center, National Marine Fisheries Service, who participated in the 12MDS study, especially those who went to sea each month over the 39 mo study period. Without the expertise of Capt. F. Farwell and S. Kingsley of the RV 'Kyma,' this study would not have been successful. We thank L. Arlen, A. Draxler, T. Finneran, and V. Zdanowicz for making their data available to us. P. Fournier helped with data management and J. Finn, A. Frame, and D. Jeffress were involved in all aspects of benthic sample processing. We also thank N. Mountford and T. Morris of Cove Corp. and H. Proctor of Normandeau Associates for processing some of the benthic samples. We appreciate the comments of A. Calabrese, S. Chang, T. Noji, A. Paulson, F. Steimle, and 3 anonymous reviewers on earlier drafts of this manuscript. C. Noonan provided editorial assistance.

\section{LITERATURE CITED}

Bopp RF, Robinson DW, Simpson HJ, Biscaye PE, Anderson RF, Tong H, Monson SJ, Gross ML (1995) Recent sediment and contaminant distributions in the Hudson Shelf Valley. In: Studholme AL, O'Reilly JE, Ingham MC (eds) Effects of the cessation of sewage sludge dumping at the 12mile site, Proc 12Mile Dumpsite Symp, NOAA Tech Rep NMFS 124, p 61-83

Botton ML (1979) Effects of sewage sludge on the benthic invertebrate community of the inshore New York Bight. Estuar Coast Mar Sci 8:169-180

Caracciolo JV, Steimle FW (1983) An atlas of the distribution and abundance of the dominant benthic invertebrates in the New York Bight apex with reviews of their life histories. NOAA Tech Rep NMFS SSRF-766

Caspers H (1987) Changes in the benthos at a sewage-sludge dumpsite in the Elbe estuary. In: Capuzzo JM, Kester DR (eds) Oceanic processes in marine pollution, Vol 1. Biological processes and wastes in the ocean. Robert E. Krieger Co., Malabar, FL, p 201-230

Chang S, Steimle FW, Reid RN, Fromm SA, Zdanowicz VS, Pikanowski RA (1992) Association of benthic macrofauna with habitat types and quality in the New York Bight. Mar Ecol Prog Ser 89:237-251

Clarke KR (1993) Non-parametric multivariate analysis of changes in community structure. Aust J Ecol 18:117-143

Clarke KR, Ainsworth M (1993) A method of linking multivariate community structure to environmental variables. Mar Ecol Prog Ser 92:205-219

Davis WR, McKinney R, Watkins WD (1995) Response of the Hudson Shelf Valley sewage sludge sediment reservoir to cessation of disposal at the 12-mile site. In: Studholme AL, O'Reilly JE, Ingham MC (eds) Effects of the cessation of sewage sludge dumping at the 12 mile site, Proc $12 \mathrm{Mile}$ Dumpsite Symp, NOAA Tech Rep NMFS 124, p 49-60

Dorsey JH, Phillips CA, Dalkey A, Roney JD, Deets GB (1995) Changes in assemblages of infaunal organisms around wastewater outfalls in Santa Monica Bay, California. Bull South Calif Acad Sci 94:46-64

Draxler AFJ (1995) Changes in sediment biogeochemistry resulting from cessation of sewage sludge dumping in the New York Bight. In: Studholme AL, O'Reilly JE, Ingham $\mathrm{MC}$ (eds) Effects of the cessation of sewage sludge dumping at the 12mile site, Proc 12Mile Dumpsite Symp. NOAA Tech Rep NMFS 124, p 133-143

Draxler AFJ, Studholme AL, Zdanowicz VS, Reid RN, Vitaliano JJ, Wilk SJ, Katz I, O'Reilly JE (1996) Closure of the New York Bight 12-mile sewage sludge dumpsite: ecosys- tem responses with implications for resource management. Northeast Geol Environ Sci 18:293-303

EPD (Environmental Processes Division) (1988) A plan for study: response of the habitat and biota of the inner New York Bight to abatement of sewage sludge dumping. NOAA Tech Memo NMFS-F/NEC-55

Gallagher ED, Jumars PA, Trueblood DD (1983) Facilitation of soft-bottom benthic succession by tube builders. Ecology 64:1200-1216

Gray JS, Wu RS, Or YY (2002) Effects of hypoxia and organic enrichment on the coastal marine environment. Mar Ecol Prog Ser 238:249-279

Hewitt JE, Thrush SE, Cummings VJ (2001) Assessing environmental impacts: effects of spatial and temporal variability at likely impact scales. Ecol Appl 11:1502-1516

Humphrey CL, Faith DP, Dostine PL (1995) Baseline requirements for assessment of mining impact using biological monitoring. Aust J Ecol 20:150-166

Manning JP, Oey LY, Packer D, Vitaliano J, Finneran TW, You KW, Fromm S (1994) Observations of bottom currents and estimates of resuspended sediment transport at the New York Bight 12-mile dumpsite. J Geophys Res 99: 10221-10239

Maurer D, Robertson G, Gerlinger T (1993) San Pedro Shelf, California: testing the Pearson-Rosenberg Model (PRM). Mar Environ Res 35:303-321

Moore DC, Rodger GK (1991) Recovery of a sewage sludge dumping ground. II. Macrobenthic community. Mar Ecol Prog Ser 75:301-308

Mountain DG, Arlen L (1995) Oceanographic conditions in the inner New York Bight during the 12-mile dumpsite study. In: Studholme AL, O'Reilly JE, Ingham MC (eds) Effects of the cessation of sewage sludge dumping at the 12mile site, Proc 12Mile Dumpsite Symp, NOAA Tech Rep NMFS 124, p 21-31

Nedwell DB, Lawson PA (1990) Degradation of digested sewage sludge in marine sediment-water model systems, and fate of metals. Mar Pollut Bull 21:87-91

Norton MG, Champ MA (1989) The influence of site-specific characteristics on the effects of sewage sludge dumping. In: Hood DW, Schoener A, Park PK (eds), Oceanic processes in marine pollution. Vol 4. Scientific monitoring strategies for ocean waste disposal. Robert E. Krieger Co., Malabar, FL, p 161-183

Packer D, Finneran T, Arlen L, Koch R, Fromm S, Finn J, Fromm SA, Draxler AFJ (1995) Fundamental and mass properties of surficial sediments in the inner New York Bight and responses to the abatement of sewage sludge dumping. In: Studholme AL, O'Reilly JE, Ingham MC (eds) Effects of the cessation of sewage sludge dumping at the 12mile site, Proc 12Mile Dumpsite Symp, NOAA Tech Rep NMFS 124, p 155-169

Pearce JB (1972) The effects of solid waste disposal on the benthic communities in the New York Bight. In: Ruivo M (ed) Marine pollution and sea life. FAO Fishing News Ltd, Surrey, p 404-411

Pearson TH (1987) Benthic ecology in an accumulating sludge-disposal site. In: Capuzzo JM, Kester DR (eds) Oceanic processes in marine pollution. Vol 1. Biological processes and wastes in the ocean. Robert E. Krieger Co., Malibar, FL, p 195-200

Pearson TH, Rosenberg R (1978) Macrobenthic succession in relation to organic enrichment and pollution of the marine environment. Oceanogr Mar Biol Annu Rev 16:229-311

Pikanowski RA (1992) The effects of ocean disposal of sewage sludge on the relative abundance of benthic megafauna. Chem Ecol 6:199-212 
Rees HL, Rowlatt SM, Lambert MA, Lees RG, Limpenny DS (1992) Spatial and temporal trends in the benthos and sediments in relation to sewage sludge disposal off the northeast coast of England. ICES J Mar Sci 49:55-64

Reid RN, O'Reilly JE, Zdanowicz VS (eds) (1982) Contaminants in New York Bight and Long Island Sound sediments and demersal species, and contaminant effects on benthos, summer 1980. NOAA Tech Memo NMFSF/NEC-16

Reid RN, Radosh DJ, Frame AB, Fromm SA (1991) Benthic macrofauna in the New York Bight, 1979-1989. NOAA Tech Rep NMFS 103

Reid RN, Fromm SA, Frame AB, Jeffress D, Vitaliano JJ, Radosh DJ, Finn JR (1995) Limited responses of benthic macrofauna and selected sewage sludge components to phaseout of sewage sludge dumping in the inner New York Bight. In: Studholme AL, O'Reilly JE, Ingham MC (eds) Effects of the cessation of sewage sludge dumping at the 12mile site, Proc 12Mile Dumpsite Symp, NOAA Tech Rep NMFS 124, p 213-225

Savage C, Elmgren R, Larsson U (2002) Effects of sewagederived nutrients on an estuarine macrobenthic community. Mar Ecol Prog Ser 243:67-82

Schaffner LC (1990) Small-scale organism distributions and patterns of species diversity: evidence for positive interactions in an estuarine benthic community. Mar Ecol Prog Ser 61:107-117

Sheppard C, Pearce J (eds) (2000) The seas at the millennium: an environmental evaluation. Mar Pollut Bull 41(1-6): $1-263$

Stehlik LL (1993) Diets of the brachyuran crabs Cancer irroratus, C. borealis, and Ovalipes ocellatus in the New York Bight. J Crustac Biol 13:723-735

Steimle FW, Caracciolo J, Pearce J (1982) Impacts of dumping on the New York Bight apex benthos. In: Mayer GF (ed)

Editorial responsibility: Otto Kinne (Editor-in-Chief), Oldendorf/Luhe, Germany
Ecological stress and the New York Bight: science and management. Estuarine Research Federation, Columbia, SC, p 213-223

Steimle FW, Jeffress D, Fromm SA, Reid RN, Vitaliano JJ, Frame A (1994) Predator-prey relationships of winter flounder, Pleuronectes americanus, in the New York Bight apex. Fish Bull 92:608-619

Stewart-Oaten A, Murdoch WW, Parker KR (1986) Environmental impact assessment: 'Pseudoreplication in time?' Ecology 67:929-940

Stewart-Oaten A, Bence JR (2001) Temporal and spatial variation in environmental impact assessment. Ecol Monogr 71:305-339

Underwood AJ (1991) Beyond BACI: Experimental designs for detecting human environmental impacts on temporal variations in natural populations. Aust J Mar Freshw Res 42: $569-587$

Underwood AJ, Chapman MG (2003) Power, precaution, Type II error and sampling design in assessment of environmental impacts. J Exp Mar Biol Ecol 296:49-70

Zajac RN, Whitlatch RB (1982) Responses of estuarine infauna to disturbance. II. Spatial and temporal variation of succession. Mar Ecol Prog Ser 10:15-27

Zdanowicz VS, Cunneff S, Finneran TW (1995) Reduction in sediment metal contamination in the New York Bight apex with the cessation of sewage sludge dumping. In: Studholme AL, O'Reilly JE, Ingham MC (eds) Effects of the cessation of sewage sludge dumping at the 12 mile site, Proc 12 Mile Dumpsite Symp, NOAA Tech Rep NMFS 124, p 89-100

Zmarzly DL, Stebbins TD, Pasko D, Duggan R M, Barwick KL (1994) Spatial patterns and temporal succession in soft bottom macroinvertebrate assemblages surrounding an ocean outfall on the southern San Diego shelf: relation to anthropogenic and natural events. Mar Biol 118: 293-307

Submitted: July 22, 2003; Accepted: January 22, 2007 Proofs received from author(s): July 6, 2007 